\title{
Characterization of biofilm formation by Escherichia coli: An in vitro study
}

\author{
Mohammad Abdulraheem AL-Kafaween ${ }^{1}$, Rao Sanaullah Khan ${ }^{2 *}$, Abu Bakar Mohd Hilmi ${ }^{1}$, Tengku Mohammad Ariff ${ }^{3}$ \\ ${ }^{1}$ Faculty of Health Sciences, University Sultan Zainal Abidin, Terengganu, Malaysia, ${ }^{2}$ School of Food and Agricultural Sciences, University of Management and \\ Technology, Lahore, Pakistan, ${ }^{3}$ Institute for Community Health Development, University Sultan Zainal Abidin, Terengganu, Malaysia
}

\section{ARTICLE INFO}

Article history:

Received on: August 05, 2018

Accepted on: August 30, 2018

Available online: April 05, 2019

\section{Key words:}

Biofilm,

Escherichia coli,

Brain heart broth,

Luria broth,

Optical density

\section{ABSTRACT}

Objective: The purpose of the present study was to characterize the effects of medium, optical density (OD), and incubation time on biofilm formation by Escherichia coli in brain heart infusion (BHI) and Luria-Bertani broth (LB). Methods: The main procedure involved fixing the bacterial film with $95 \%$ ethanol, staining with $0.1 \%$ crystal violet, releasing the bound dye with $33 \%$ glacial acetic acid, and measuring the OD of the solution at $570 \mathrm{~nm}$ using a microplate reader. Results: It was found that 3 and 5 days of incubation are critical for biofilm formation as indicated by the OD values of $0.55-0.35$ and $0.70-0.39$ in BHI and LB, respectively, at OD 0.05 . Similarly, pattern in results was noted for OD 0.1 in both media BHI and LB. Conclusion: It is confirmed that 3 days $(72 \mathrm{~h})$ are required for obtaining effective biofilm formation in both $\mathrm{BHI}$ and $\mathrm{LB}$ at $37^{\circ} \mathrm{C}$ at $\mathrm{OD} 0.05$ and 0.1 .

\section{INTRODUCTION}

Biofilm formation as a bacterial defense mechanism is difficult to break-in with traditional medical treatment tools such as antibiotics. The integrated colonization of bacteria on the surface of the host which is supported by the thick extracellular secretions termed as a biofilm [1,2,3]. Biofilms are more resistant toward antibiotics compared to its planktonic state [1,4] and account for $>80 \%$ of infections in human body [3]. Hence, it is of crucial importance to understand biofilm formation and associated factors that can effectively be controlled in designing new clinical treatments.

Biofilm formation of pathogenic strains of Escherichia coli is considered to be a virulence factor in a host with compromised immune system [5,6,7]. Biofilm formation is well studied in E. coli; however, a greater genomic variability coupled with diverse environmental niches leaves a huge task for biofilm formation mechanism exploration $[5,7]$. Based on its genetic variation, this species has been divided into six phylogenetic groups, i.e., A, B1, B2, C, D, and E using triplex PCR phylogroup assignment methods $[6,7,8]$. Hence, it is quite diverse in its mode of habitat and defense mechanisms. It is critically important to model in vitro study to reveal its biofilm formation patterns.

*Corresponding author:

Rao Sanaullah Khan, Institute for Community (Health) Development,

University Sultan Zainal Abidin, Terengganu, Malaysia.

E-mail:rsukhan83@gmail.com
In this study, an in vitro model study has been designed to investigate the effect of media type, initial optical density (OD), and incubation time in two different growth media, i.e., brain heart infusion (BHI) and Luria-Bertani broth (LB) for better understanding of biofilm formation by E. coli [9]. BHI medium is useful for cultivating a wide variety of microorganisms since it is a highly nutritive medium [9]. $\mathrm{BHI}$ is also used for the preparation of inoculum in antimicrobial susceptibility testing. While Luria-Bertani broth (LB) is generally used for molecular and genetic studies due to its nutritive capacity and simple composition that can be easily modified. Moreover, LB is used for the cultivation and maintenance of recombinant strains of $E$. coli, originally derived from $E$. coli strain $\mathrm{K} 12$, deficient in Vitamin B production. LB is a nutritionally rich medium due to the presence of casein enzymic hydrolysate and yeast extract [10]. This allows their recombinant strains of $E$. coli to grow more rapidly since all the essential growth nutrients required by these strains are readily available; thus, there is no need to synthesize it [11]. Therefore, in this study, the biofilm formation has been compared in two media, i.e., BHI and LB at varying OD with the following hypothesis;

$\mathrm{H}_{1}$ : Initial turbidity of the bacteria (OD) has no significant effect on biofilm formation.

$\mathrm{H}_{2}$ : Incubation time (days) has no significant effect on biofilm formation.

$\mathrm{H}_{3}$ : Interaction of initial turbidity of the bacteria (OD) and incubation time (days) has no significant effect on biofilm formation. 


\section{MATERIALS AND METHODS}

\subsection{Bacterial Growth}

E. coli strain (ATCC 25922) commonly associated with catheterassociated infections and food safety danger was used in this study. E. coli was grown in BHI culture media. After inoculation, broth was incubated at $37^{\circ} \mathrm{C}$ for $24 \mathrm{~h}$. From these cultures, a suspension of $E$. coli $(0.1 \%)$ was prepared in BHI broth and $100 \mu \mathrm{L}$ of this suspension was pipetted into the wells of the 96 -well plate $[12,13]$. These plates were incubated for 24,48 , and $72 \mathrm{~h}$ at $37^{\circ} \mathrm{C}$. The supernatant from wells, containing planktonic bacteria, was gently aspirated to clear flatbottomed 96-well plates for the measurement of absorbance at $570 \mathrm{~nm}$.

\subsection{Biofilm Assay}

For biofilm assay, bacterial growth media and cells were removed and wells were rinsed 3 times with $150 \mu \mathrm{L}$ of sterile distilled water without disturbing the adherent biofilm. The plates were air-dried for $5 \mathrm{~min}$. Wells were attained with $120 \mu \mathrm{L}$ of crystal violet $(0.1 \%)$ for $15 \mathrm{~min}$ at room temperature [13]. The crystal violet was removed and the wells were rinsed 3 times with $150 \mu \mathrm{L}$ of distilled water and left to air dry. Subsequently, $150 \mu \mathrm{L}$ of $95 \%$ ethanol per well was applied and the plates were incubated at room temperature for $15 \mathrm{~min}$. The contents of each well were thoroughly mixed and $125 \mu \mathrm{L}$ of the crystal violet/ethanol solution was transferred to a clear flat-bottomed 96-well plate. The extent of biofilm formation was determined by measuring absorbance at $570 \mathrm{~nm}[2,12,14,15]$.

\subsection{Biofilm Analysis}

The cutoff was defined as three standard deviations above the mean OD of the negative control (ODc) which contained broth only. The following criteria were used to classify the different adherent strength: $\mathrm{OD} \leq \mathrm{OD}_{\mathrm{C}}=$ non-adherent, $\mathrm{OD}_{\mathrm{C}}<\mathrm{OD} \leq\left(2 \times \mathrm{OD}_{\mathrm{C}}\right)=$ weakly adherent, $\left(2 \times \mathrm{OD}_{\mathrm{C}}\right)<\mathrm{OD} \leq\left(4 \times \mathrm{OD}_{\mathrm{C}}\right)=$ moderately adherent, and $\left(4 \times \mathrm{OD}_{\mathrm{C}}\right)$ $<\mathrm{OD}=$ strongly adherent $[16]$.

\subsection{Statistical Analysis}

All the trials were conducted in triplicate to calculate the mean and standard deviations of the data collected. One-way repeated measure ANOVA was conducted to compare the effect of incubation time on biofilm formation in $\mathrm{BHI}$ and $\mathrm{LB}$ at 0.05 and 0.1 initial OD values $[13,17]$.

\section{RESULTS AND DISCUSSION}

Biofilm formation was noted to be higher in the first 3 days of incubation in both media (BHI and LB), then it started to slow down till on the $7^{\text {th }}$ day; biofilm formation was negligible [Figure 1]. Further, it was noticed that OD 0.05 and 0.1 , in both BHI and LB, had similar biofilm formation progress [Figure 1] with day 3 and day 5 being strongly adherent $\left(\left(4 \times \mathrm{OD}_{\mathrm{C}}\right)<\mathrm{OD}\right)$ [Table 1$]$.

However, it was also observed that LB is more effective at OD 0.05 than HBI, whereas HBI was more effective at $0.1 \mathrm{OD}$ in biofilm formation progress.

\subsection{Biofilm Characterization}

Based on the OD values, biofilm was characterized into various categories such as strongly adherent, weakly adherent, and no adherence [Table 1]. It was found that there was a strong adherence at 3 days of incubation at both OD 0.05 and 0.10 for both media (BHI and LB).
To further explore the relationship, if any, between OD values and media, two-way ANOVA was performed, wherein variable factors were OD values and incubation time (days) [Table 2]. It was found that OD has a significant effect on biofilm formation $(P=0.0106$ and $P<0.05)$. Therefore, null hypothesis $\mathrm{H}_{1}$ is rejected. Similarly, days of incubation had significant effect on biofilm formation $(P<0.05)$; reject the second hypothesis. However, it was observed that the interaction of OD values and days of incubation had a non-significant effect on biofilm formation $\left(\mathrm{H}_{3}\right)$.

To further investigate which day and OD concentration is more effective in biofilm formation, Tukey's multiple comparison test was also performed to check the significance of time (days) on biofilm formation in both media. It showed that the time (days) had a significant effect $(P<0.05)$ on biofilm formation [Table 3] under both 0.05 and $0.10 \mathrm{OD}[13]$.

Therefore, it can be concluded that $72 \mathrm{~h}$ of incubation at $37^{\circ} \mathrm{C}$ is the ideal time for biofilm formation in BHI and LB for E. coli. Similar study was conducted by Low et al., [9] where the growth of $E$. coli was monitored for 11 weeks in three different media.

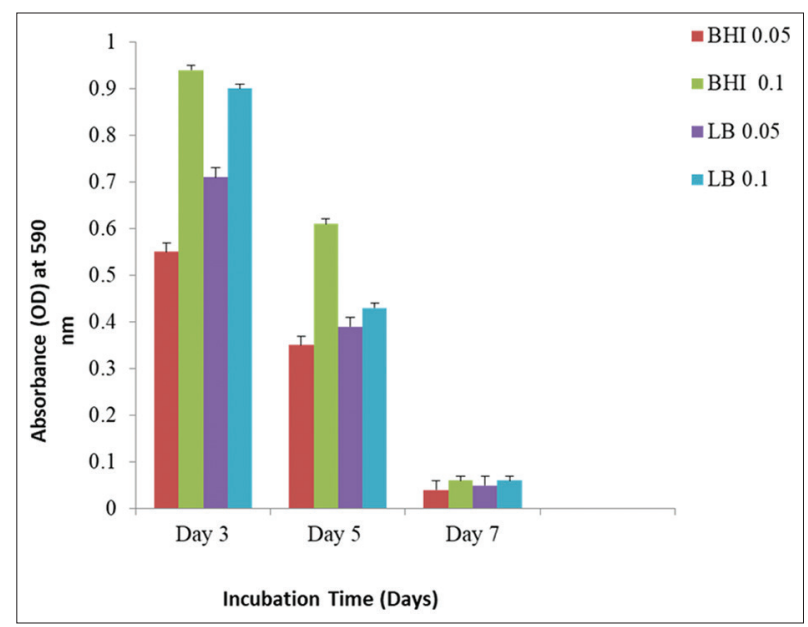

Figure 1: Biofilm formation by Escherichia coli in brain heart infusion and Luria-Bertani broth media

Table 1: Characterization of biofilms based on OD values

\begin{tabular}{lccccc} 
Times (day) & Control & BHI 0.05 & BHI 0.1 & LB 0.05 & LB 0.1 \\
Day 3 & 0.06 & $0.55 \mathrm{SA}$ & $0.94 \mathrm{SA}$ & $0.71 \mathrm{SA}$ & $0.9 \mathrm{SA}$ \\
Day 5 & 0.06 & $0.35 \mathrm{SA}$ & $0.61 \mathrm{SA}$ & $0.39 \mathrm{SA}$ & $0.43 \mathrm{SA}$ \\
Day 7 & 0.06 & $0.04 \mathrm{WA}$ & $0.06 \mathrm{WA}$ & $0.05 \mathrm{WA}$ & $0.06 \mathrm{WA}$ \\
\hline
\end{tabular}

$\mathrm{OD} \leq \mathrm{OD}_{\mathrm{C}}=$ Non-adherent, $\mathrm{OD}_{\mathrm{C}}<\mathrm{OD} \leq\left(2 \times \mathrm{OD}_{\mathrm{C}}\right)=$ Weakly adherent, $\left(2 \times \mathrm{OD}_{\mathrm{C}}\right)<\mathrm{OD}$ $\leq\left(4 \times \mathrm{OD}_{\mathrm{C}}\right)=$ Moderately adherent, and $\left(4 \times \mathrm{OD}_{\mathrm{C}}\right)<\mathrm{OD}=$ Strongly adherent. BHI: Brain heart infusion, LB: Luria-Bertani broth

Table 2: Two-way ANOVA for determining critical factors in biofilm formation

\begin{tabular}{lccccc} 
Factors & SS & DF & MS & F (DFn, DFd) & $P$ value \\
Interaction & 0.03763 & 2 & 0.01882 & $\mathrm{~F}(2,6)=3.715$ & $P=0.0892$ \\
OD & 0.06785 & 1 & 0.06785 & $\mathrm{~F}(1,6)=13.40$ & $P=0.0106^{*}$ \\
$\begin{array}{l}\text { Incubation } \\
\text { days }\end{array}$ & 1.05 & 2 & 0.5251 & $\mathrm{~F}(2,6)=103.7$ & $P<0.0001^{*}$ \\
Residual & 0.03039 & 6 & 0.005065 & & \\
\hline
\end{tabular}

SS: Sum of squares, DF: Degree of freedom, MS: Mean square F (DFn, DFd $)=$ F distribution, ${ }^{*} P<0.05$ considered statistically significant 
Table 3: Two-way ANOVA with Tukey's multiple comparison tests

\begin{tabular}{lccccc}
$\begin{array}{l}\text { Tukey's multiple } \\
\text { comparison }\end{array}$ & Mean 1 & Mean 2 & $\begin{array}{c}\text { Mean } \\
\text { diff. }\end{array}$ & $\begin{array}{c}\text { SE of } \\
\text { diff. }\end{array}$ & $\begin{array}{c}\text { Adjusted } \\
\boldsymbol{P} \text { values }\end{array}$ \\
$\begin{array}{l}\text { Day 3 versus } \\
\text { day 5 }\end{array}$ & 0.7736 & 0.445 & 0.3286 & 0.097 & 0.1372 \\
$\begin{array}{l}\text { Day 3 versus } \\
\text { day 7 }\end{array}$ & 0.7736 & 0.05 & 0.7236 & 0.097 & $* 0.0318$ \\
$\begin{array}{l}\text { Day 5 versus } \\
\text { day 7 }\end{array}$ & 0.445 & 0.05 & 0.395 & 0.097 & 0.0992 \\
\hline *Significant & & & & & \\
\hline
\end{tabular}

\section{CONCLUSION}

Time interval for biofilm formation is critical in BHI and LB. The biofilm formation growth follows a sinusoidal pattern, wherein a peak of biofilm formation achieved in $72 \mathrm{~h}$ of incubation and then decline gradually until the $7^{\text {th }}$ day. Overall, it can be deducted from this study that $\mathrm{BHI}$ and $\mathrm{LB}$ can give maximum biofilm formation by $E$. coli within $72 \mathrm{~h}$ of incubation period. However, further, investigation is recommended to reveal the biofilm formation pattern in $E$. coli under variable environment to model better remedial pathways in controlling infections. Moreover, a quantitative analysis of biofilm can reveal structural component of biofilm.

\section{ACKNOWLEDGMENTS}

This important piece of research would have not been possible without the generous support of all the staff members of the Faculty of Health Sciences and Microbiology Laboratory Technicians at University Sultan Zainal Abidin, Terengganu, Malaysia.

It is declared here by the authors of this article that there are no conflicts of interest in writing and publishing these research findings.

\section{REFERENCES}

1. Mah TF, O'Toole GA. Mechanisms of biofilm resistance to antimicrobial agents. Trends Microbiol 2001;9:34-9.

2. Ng WJ, Chan YJ, Lau ZK, Lye PY, Ee KY. Antioxidant properties and inhibitory effects of trigona honey against Staphylococcus aureus planktonic and biofilm cultures. Int J GEOMATE 2016;12:28-33.

3. Davies D. Understanding biofilm resistance to antibacterial agents. Nat Rev Drug Discov 2003;2:114.

4. Merckoll P, Jonassen TO, Vad ME, Jeansson SL, Melby KK. Bacteria, biofilm and honey: A study of the effects of honey on 'planktonic' and biofilm-embedded chronic wound bacteria. Scand J Infect Dis
2009;41:341-7.

5. Rossi E, Cimdins A, Lüthje P, Brauner A, Sjöling Å, Landini P, et al. "It's a gut feeling" -Escherichia coli biofilm formation in the gastrointestinal tract environment. Crit Rev Microbiol 2018;44:1-30.

6. Touchon M, Hoede C, Tenaillon O, Barbe V, Baeriswyl S, Bidet P, et al. Organised genome dynamics in the Escherichia coli species results in highly diverse adaptive paths. PLoS Genet 2009;5:e1000344.

7. Van Elsas JD, Semenov AV, Costa R, Trevors JT. Survival of Escherichia coli in the environment: Fundamental and public health aspects. ISME J 2010;5:173.

8. Clermont O, Christenson JK, Denamur E, Gordon DM. The Clermont Escherichia coli phylo-typing method revisited: Improvement of specificity and detection of new phylo-groups. Environ Microbiol Rep 2013;5:58-65.

9. Low SX, Aw ZQ, Loo BZ, Lee KC, Oon JS, Lee CH, et al. Viability of Escherichia coli ATCC 8739 in nutrient broth, luria-bertani broth and brain heart infusion over 11 weeks. Electron Physician 2013;5:576-81.

10. Sambrook H. Molecular Cloning: A Laboratory Manual. Cold Spring Harbor, NY: Cold Spring Harbor Laboratory Press; 1989.

11. Ausubel F, Brent R, Kingston RE, Moore DD, Seidman J, Smith JA, et al. Current Protocols in Molecular Biology. New York: Wiley; 1987.

12. Shehu A, Ismail S, Adzim M, Rohin MA, Harun A, Aziz AA, et al. Antifungal properties of Malaysian tualang honey and stingless bee propolis against Candida albicans and Cryptococcus neoformans. J Appl Pharm Sci 2016;6:44-50.

13. Nyenje ME, Green E, Ndip RN. Evaluation of the effect of different growth media and temperature on the suitability of biofilm formation by Enterobacter cloacae strains isolated from food samples in South Africa. Molecules 2013;18:9582-93.

14. Rao PV, Krishnan KT, Salleh N, Gan SH. Biological and therapeutic effects of honey produced by honey bees and stingless bees: A comparative review. Rev Bras Farmacognosia 2016;26:657-64.

15. Nassar HM, Li M, Gregory RL. Effect of honey on Streptococcus mutans growth and biofilm formation. Appl Environ Microbiol 2012;78:536-40.

16. Basson A, Flemming L, Chenia H. Evaluation of adherence, hydrophobicity, aggregation, and biofilm development of Flavobacterium johnsoniae-like isolates. Microb Ecol 2008;55:1-14.

17. Prism G. Two Way ANOVA (Version 7.04). La Jolla California USA: Graph Pad Software Inc.; 2018.

\section{How to cite this article:}

AL-Kafaween MA, Khan RS, Hilmi ABM, Ariff TM. Characterization of biofilm formation by Escherichia coli: An in vitro study. J App Biol Biotech. 2019;7(03):17-19. DOI: 10.7324/JABB.2019.70304 